\title{
A ESCOLA DE TODAS AS CORES: o papel do gestor escolar no combate ao racismo
}

\author{
Helena de Lima Marinho Rodrigues Araújo' \\ Aline Cristina Clemente Braga²
}

\section{RESUMO}

O racismo é um tema ainda bastante discutido sob vários enfoques: sociológico, antropológico, filosófico, educacional, entre outros. A escola é um lócus por excelência para 0 debate e propostas de mudanças para disseminar 0 conhecimento e a necessidade de priorizar o direito de todos viverem bem no mundo. Este artigo teve por objetivo conhecer o papel do gestor escolar no combate ao racismo nos anos iniciais do Ensino Fundamental. As referências teóricas utilizadas para respaldar a análise dos dados foram focadas em artigos científicos, documentos e livros, destacando os seguintes autores: Macedo (2014), Pereira (2012), Rodrigues (2011) e Schucman (2010). Elegeu-se a análise qualitativa dos dados, por meio de entrevista semiestruturada com uma coordenadora de uma escola pública e uma diretora de uma escola privada, sendo essas instituições localizadas em um mesmo bairro do município de Fortaleza, no estado do Ceará. As entrevistas revelaram que o tema racismo é tratado com o diálogo e que há a participação da gestão para a resolução de problemas, tendo-se ciência dos recursos disponíveis para trabalhar o tema. De outro ângulo, mostraram pouca desenvoltura no tocante às leis e aos trabalhos com projetos nas escolas que abordem o racismo de forma mais constante como parte do currículo escolar.

Palavras-chave: Preconceito racial. Gestão escolar. Ensino-aprendizagem.

\section{THE SCHOOL OF ALL COLORS: the role of the school manager does not fight racism}

\begin{abstract}
Racism is a topic that is still widely discussed under several approaches: sociological, anthropological, philosophical, and educational, among others. We consider the School a locus par excellence for debate and proposals for changes to disseminate knowledge and the need to prioritize the right of everyone to live well in the world. This

1 Pós-Doutora em Educação. Docente da Universidade Estadual do Ceará (UECE). E-mail: helena.marinho@vece.br

2 Especialista em Gestão Escolar. Docente da Educação Básica. E-mail: cristina.braga@aluno.vece.br
\end{abstract}


article aimed at knowing the role of the school manager in the fight against racism in the early years of Elementary School. The theoretical references used to support the analysis of the data were focused on scientific articles, documents and books, highlighting the following authors: Macedo (2014), Pereira (2012), Rodrigues (2011) and Schucman (2010). We chose the qualitative data analysis, through a semi structured interview with a coordinator of a public school and a director of a private school, institutions located in a neighborhood of Fortaleza County in the state of Ceará. The interviews revealed that the racism theme is treated with the dialogue, that there is the participation of the management to solve problems, and they are aware of the resources available to work on the theme. From another angle, they have shown little resourcefulness about laws and project work in schools that address racism more consistently as part of the school curriculum.

Keywords: Racial prejudice. School management. Teaching-learning.

\section{LA ESCUELA DE TODOS LOS COLORES: el papel del director escolar en el combate al racismo}

\section{RESUMEN}

El racismo es un tema aún bastante discutido bajo varios enfoques: sociológico, antropológico, filosófico, educativo, entre otros. Consideramos a la escuela un local por excelencia para el debate y propuestas de cambios para diseminar el conocimiento y la necesidad de priorizar el derecho de todos a vivir bien en el mundo. Este artículo tuvo por objetivo conocer el papel del director escolar en el combate al racismo en los años iniciales de la Enseñanza Fundamental. Las referencias teóricas utilizadas para respaldar el análisis de los datos se enfocaron en artículos científicos, documentos y libros, destacando los siguientes autores: Macedo (2014), Pereira (2012), Rodrigues (2011) y Schucman (2010). Se elegió el análisis cualitativo de los datos por medio de una entrevista semiestructurada con una coordinadora de una escuela pública y una directora de una escuela privada, instituciones ubicadas en un mismo barrio del municipio de Fortaleza, en el estado de Ceará. Las entrevistas revelaron que el tema del racismo es tratado con el diálogo y con la participación de la dirección para la resolución de problemas, la cual tiene ciencia de los recursos disponibles para trabajar el tema. Desde otro ángulo, mostraron poca desenvoltura en cuanto a las leyes y trabajos con proyectos en las escuelas que aborden el racismo de forma más constante como parte del currículo escolar.

Palabras clave: Prejuicio de raza. Gestión escolar. Enseñanza y aprendizaje.

\section{INTRODUÇÃO}

A escravidão no Brasil durou 358 anos; já se passaram 130 anos desde a sua abolição, mas as sequelas desse período obscuro permanecem em nossa sociedade. O preconceito racial ainda está enraizado em nosso 
cotidiano, ocorrendo de forma direta ou indireta. Encontramos o preconceito em ditados populares, marchinhas e fantasias de Carnaval; nomenclaturas na forma como ocorre a abordagem policial; na intolerância religiosa; nas atitudes e olhares.

Cada vez mais, tomamos conhecimento de que um dos povos que deram origem à população brasileira foram os africanos e que a sua cultura se tornou um dos pilares para a construção da nossa cultura. A mão de obra negra transformou o Brasil na potência econômica que hoje conhecemos, porém serviu para enriquecer uma minoria. Por tudo isso e pelos 358 anos de sofrimento, o Brasil ainda mantém uma dívida histórica com os nossos irmãos afrodescendentes que é reconhecida pelos livros de História, pelos meios de comunicação e pela legislação pátria, mas na prática ainda encontramos dificuldades para que ela seja efetivada.

A representatividade para toda a humanidade é importante, contudo a maior parte dos exemplos de beleza, de heroísmo e de realeza que são aplaudidos nacionalmente e/ou internacionalmente relaciona-se a indivíduos brancos, exemplificando: no meio acadêmico, há predominância de sujeitos de cor branca3; os protagonistas das novelas são na maioria brancos; a boneca símbolo da beleza - "Barbie" - faz referência à mulher branca; nas capas de revistas, as modelos são brancas em sua maioria; e os nossos heróis em quadrinhos são predominantemente brancos.

O fato suscitado nos faz refletir sobre como é difícil ser negro no Brasil e no mundo. Isso fica claro quando passamos por um corredor de uma loja de brinquedos; poucos são os bonecos negros se comparados à quantidade de bonecos brancos. Isso acaba influenciando negativamente na imagem da própria criança branca e, sobretudo da criança negra, que não se reconhece nesses brinquedos. Isso fica claramente perceptível também em um dos ambientes de convívio social delas - a escola.

3 Cenário que hoje apresenta mudanças por incentivo da Lei de Cotas $n^{\circ} 12.711$, de 29 de agosto de 2012. Dispõe sobre o ingresso nas universidades federais e nas instituições federais de ensino técnico de nível médio e dá outras providências (BRASIL, 2012). 
Nos dias de hoje em nossas salas de aula, percebemos que temos turmas "coloridas" por diferentes tons de pele, e isso é natural por conta da nossa miscigenação. Porém, observamos em nossa prática pedagógica que o preconceito racial, proliferado pelas próprias crianças nas salas das séries iniciais do Ensino Fundamental, vai se tornando recorrente, mas a questão é: onde estão aprendendo essas práticas? Estamos nos reportando a crianças que estão em processo de constituição, as quais tendem a refletir as ações que veem dos próprios adultos, jovens e até outras crianças, por conseguinte, podendo aprender em qualquer lugar que a criança frequente, incluindo a escola.

Em sala de aula, observamos dois casos que nos chamaram a atenção: o primeiro referia-se a um desenho feito por uma criança de 7 anos em que deveriam ser retratados os alunos da sala; nesse desenho, todas as crianças tinham a pele clara, eram loiras, de olhos azuis e cabelos lisos, mas não havia ninguém com tais características na sala. E, diferentemente do desenho, a própria criança que o havia concebido era uma linda menina negra, de belos cabelos crespos e encantadores olhos castanhos escuros. O segundo referiase a um menino negro chamando outra aluna negra de "macaca". Questionamos o porquê daquele cognome, e ele disse que era por causa da cor dela. Convidamos os dois para irem à frente da sala e thes solicitamos que estendessem os braços, em seguida perguntamos ao menino se a cor da colega dele era igual à dele e depois Ihe fizemos o questionamento: "Você gostaria que the chamassem de 'macaco'?".

O que estamos fazendo com as nossas crianças? Ao buscar o amparo do núcleo gestor da instituição, percebemos certo descaso, e essa situação nos levou a refletir sobre qual o papel do gestor no combate ao racismo. Sabemos que esse mal deve ser combatido e que, no âmbito escolar, devemos contar com o apoio da gestão, pois é também seu papel combater qualquer tipo de discriminação que ocorra e que traga algum tipo de conflito na escola. Com base nesse contexto, justificamos esta pesquisa acadêmica, 
que teve como questionamento norteador: "Qual é o papel do gestor no combate ao racismo nas séries iniciais do Ensino Fundamental?".

Nesta pesquisa, tivemos por objetivo primordial conhecer o papel do gestor escolar no combate ao racismo nos anos iniciais do Ensino Fundamental e por objetivos específicos: diagnosticar o trabalho de combate ao racismo nas escolas campos da pesquisa; identificar se há algum projeto ou prática docente que confronte o racismo nos anos iniciais do Ensino Fundamental; e verificar se o gestor promove a igualdade racial dentro do ambiente escolar.

As referências teóricas utilizadas para respaldar a análise dos dados foram focadas em artigos científicos, documentos e livros, destacando-se os seguintes autores: Macedo (2014), Pereira (2012), Rodrigues (2011) e Schucman (2010).

No trajeto metodológico, elegemos a análise qualitativa dos dados, por meio de entrevista previamente estruturada com uma coordenadora de uma escola pública - denominada CEPU - e uma diretora de uma escola privada - denominada DEPr, sendo essas instituições localizadas em um mesmo bairro do município de Fortaleza, Ceará. Justificamos essas escolhas da coordenadora e da gestora por conta de nossa pergunta norteadora, que indaga sobre o papel do gestor no combate ao racismo nas séries iniciais do Ensino Fundamental. No tocante às escolas, ressaltamos a questão da proximidade, por serem sediadas no mesmo bairro, e também a questão da diferença entre ensino público e privado.

No ambiente acadêmico, a discussão sobre o preconceito racial é recente e frequente, dessa forma é um assunto que merece atenção para garantir o direito de todos, especialmente aqueles direitos que são, por vezes, negados por esse motivo. O artigo foi estruturado da seguinte maneira: "Introdução", "Racismo no Brasil", "O gestor e o combate ao racismo na escola", "Metodologia", "Análise dos dados" e "Conclusão". 


\section{RACISMO NO BRASIL}

O racismo originou-se a partir de um sentimento de superioridade nutrido por nossos colonizadores portugueses, bem como por todos os europeus. Eles consideravam-se superiores aos demais povos, sentiam-se eleitos para dominarem aqueles que por eles eram considerados inferiores. Por essa razão, ao colonizarem uma região essa nova colônia era obrigada a deixar seus costumes e crenças para "abraçar" a religião e a cultura europeias.

É válido ressaltar que no princípio o racismo não possuía as características que hoje conhecemos bem, ele assemelhava-se a outro crime que hoje conhecemos como xenofobia. Foi com essa ideia errônea de "raça superior" que os portugueses fizeram os primeiros contatos com os africanos. Esse sentimento de superioridade serviu de justificativa para a escravização, escondendo o real motivo de tal atrocidade: a ganância. Sobre o assunto, Siqueira (2010, p. 129) releva que:

Os escravos chegavam em navios negreiros abarrotados e em condições degradantes de acomodação, saúde e higiene, como se animais fossem. Eles eram usados para o serviço doméstico e, também, para o serviço externo nas fazendas, principalmente nas lavouras de cana-de-açúcar. Os escravos negros serviam, ainda, como mercadorias que podiam ser trocadas por outras. Portanto, 0 negro era tido como objeto e nunca como sujeito de direito.

O tráfico negreiro foi a maior fonte de renda do Período Colonial. Para justificar tamanho absurdo, foram utilizadas diversas desculpas, como: "O negro é uma raça inferior"; "O negro não tem alma"; "O negro é sujo"; ou até mesmo "O negro não é digno de pena". Tais desculpas eram repetidas e repassadas para os seus descendentes. Vistos como seres de raça inferior, os negros eram tratados de forma desumana e trabalhavam arduamente, eram mal alimentados, viviam em senzalas, tinham os seus filhos arrancados de seus cuidados, tinham seus direitos básicos negados e sofriam todo tipo de tortura; especificamente com relação às mulheres, em muitos casos, sofriam abusos por parte dos "seus" senhores. A miscigenação que hoje 
podemos ver em nosso Brasil aconteceu, não raro, de forma traumática e vergonhosa. Destaca Pereira $(2012$, p. 4) que:

É possível perceber um país constituído por sequelas que o tempo jamais será capaz de apagar: um solo brasileiro identificado pelo sangue derramado de milhares de africanos abruptamente sequestrados de seu país e coagidos a trabalhar em uma terra por eles desconhecida. Entretanto, não foi o desconhecimento dessa terra o motivo negativo que serviu para justificar a imensa barbárie da escravidão, e sim a recepção e as diversas formas que o homem branco utilizou para impor sua vã soberania. Uma vez jogados em solo brasileiro, os negros e todos os seus descendentes ficaram à deriva dos maus-tratos e das mais diversas formas criativas de invisibilidade humana. Destratados, não raras vezes, os negros escravos se questionaram o porquê de suas vidas serem inferiores à de um cavalo, por exemplo.

Mas o que é racismo? O que é considerado racismo? Schucman (2010, p. 44) caracteriza bem o racismo quando diz que é "[...] qualquer fenômeno que justifique as diferenças, preferências, privilégios, dominação, hierarquias e desigualdades materiais e simbólicas entre seres humanos, baseado na ideia de raça". O racismo nascido no período colonial foi repassado de geração a geração, criando raízes tão profundas em nossa sociedade que até hoje, em pleno século XXI, não conseguimos extingui-lo. Ele cristalizou em nosso meio inverdades sobre o negro e sobre a cultura africana. Uma das piores, se não a pior, é considerarem o negro como "raça inferior", pois é biologicamente comprovado que não há duas ou mais raças humanas, mas apenas uma, que apresenta cores de pele e traços físicos diferentes. No entanto, ainda são crescentes os casos de preconceitos no Brasil.

O preconceito racial é a ideia ou conceito sem qualquer fundamento real sobre uma determinada pessoa, baseado apenas em concepção prévia de cunho ideológico pessoal. No que concerne a esse assunto, Schucman (2010, p. 44) expressa que:

Ainda que todas as evidências apontem o racismo como explicação para as desigualdades raciais, o racismo brasileiro tem a especificidade de ser velado e sutil. A ideia de 'democracia racial' faz parte do imaginário brasileiro e constrói um ideal do qual os

Revista Exitus, Santarém/PA, Vol. 9, N² 2, p. 263 - 291, ABR/JUN 2019. 
brasileiros, em sua maioria, não abrem mão. Hasenbalg (1979) aponta que a ideia de democracia racial é uma arma ideológica produzida por intelectuais das elites dominantes brancas, destinada a socializar a população brasileira de brancos e não brancos como iguais, evitando, desta forma, um conflito racial no Brasil.

A Lei $n^{\circ} 7.716 / 1989$ passou a criminalizar toda atitude de preconceito racial. A intenção dessa lei foi a de acabar com atitudes preconceituosas, mas ela não conseguiu ainda dissipar todos os "nãos" que o negro recebe ao procurar emprego ou a predominância de sujeitos de cor branca em altos cargos da nossa sociedade, tampouco mudou os olhares de repúdio que muitos negros recebem diariamente unicamente em razão da cor de sua pele. Como criminalizar um crime que acontece veladamente?

No Brasil, por saberem que é crime, as pessoas não cometem racismo diretamente nem assumem que o nosso país é preconceituoso, descartando logo a hipótese de que há preconceito em nosso meio. Em todo o Brasil, os locais cuja moradia é precária (por falta de saneamento básico, coleta de lixo, enfim, por serem locais de risco) são chamados de favelas, conjunto de habitações composto, sobretudo por negros. A maioria dos que cursam as graduações mais estimadas, como a de Medicina, é composta por indivíduos brancos. A predominância de pessoas da cor negra encontra-se nas cadeias, no desemprego, no analfabetismo e nos altos índices de mortalidade. Pereira $(2012$, p. 2) contribui para a discussão quando salienta que:

Basta uma simples situação pontual para nos depararmos com essas arestas: a significativa ausência de negros em instituições de ensino e os reduzidos 'cargos de chefia' por eles exercidos nas grandes empresas e indústrias brasileiras. Nas instituições de ensino a realidade é a mesma: um número relativamente baixo de alunos negros, se comparados com os alunos brancos, além da evasão escolar/universitária relativamente alta entre os negros que lá se encontram somada aos raros casos de êxito acadêmico. Porém, é importante afirmar que não é a dificuldade cognitiva que falta para esses alunos, e sim a imutabilidade de uma realidade social que, ao menosprezar a educação como direito, naturaliza a dificuldade financeira da maioria dos negros em nosso país, gerando as mais perversas desigualdades entre pessoas. 
A falta de oportunidades de crescimento educacional e profissional assombrou a população negra desde o dia da abolição da escravatura, para sermos mais precisos, desde o dia 13 de maio de 1888, quando a princesa Isabel foi pressionada pelos abolicionistas e pelos países que já haviam abolido a escravidão a libertar os cativos. O Brasil foi o último país independente a abolir a escravidão, não tendo havido nenhum preparo sobre como seria a vida dos negros a partir daquele dia. Não houve medidas para que tivessem moradias, terras para trabalhar, trabalho em qualquer âmbito, enfim, nada foi ofertado para aqueles que tanto fizeram pelo nosso país.

A liberdade da escravidão veio junto com o peso de não saber o que fazer ou para onde ir. Além disso, logo vieram imigrantes europeus para trabalharem nas fazendas e nos cafezais, ou seja, os negros tinham que competir por empregos com pessoas brancas, as quais, por vezes, eram mais qualificadas e não carregavam o amargo excludente da escravidão que na época era recente. Já se passaram 130 anos desde a Lei Áurea, mas infelizmente a marginalização do negro ainda persiste. É por essa razão que até hoje a maior parte da população pobre ainda é negra.

Diante do que foi exposto, fica perceptível como é difícil ser negro no Brasil. Por essa razão, muitos não conseguem se identificar como negro, pois a nomenclatura em si já é sinônimo de preconceito e perda de oportunidades, infelizmente. Sendo assim, alguns negros negam a sua identidade, intitulando-se "pardos" ou "morenos", fugindo da sua ancestralidade e cultura de origem. No entanto, há pessoas que lutam (movimentos sociais, políticas afirmativas - dentre elas, a de Cotas -, programas sociais, dentre outros) para mudar esse quadro de origem, abraçando e promovendo a sua identidade racial. Esses sujeitos utilizam e transformam a ideia pejorativa de "raça" em uma arma a favor da negritude, demonstrando orgulho de serem afrodescendentes.

Os negros militantes orgulham-se de suas raízes e lutam por igualdade de direitos na saúde, na educação, na cultura e também na fé. Temos em 
nossa cultura muitos elementos de matrizes africanas, seja em remédios, na música, no esporte, na religião, nas comidas e nos costumes. Todos esses elementos são vistos como patrimônios nacionais, motivos de orgulho para nós, brasileiros, o que torna o Brasil tão contraditório: o mesmo país que cresceu economicamente à custa de suor e sangue negro, que se expande "turisticamente" promovendo elementos culturais de matrizes africanas, é o mesmo que discrimina, marginaliza e mata afrodescendentes.

Outra contradição é a utilização de elementos do vestuário africano por pessoas brancas, as quais passam a ser vistas como modernas, sendo muito elogiadas por outras pessoas brancas. São exemplos desses elementos: roupas com estampas africanas, turbantes, dreads (uso de lã em penteados) e trancinhas nos cabelos. Porém, se algum afrodescendente utilizar qualquer um desses elementos, pode ser vítima de hostilização e preconceito. Se analisarmos bem essa situação, perceberemos então que se trata de uma apropriação cultural, pois a cultura negra, muitas vezes, só é aceita quando praticada por pessoas de pele clara.

A apropriação cultural não é algo recente, mas sim as denúncias sobre esse comportamento questionável, pois o advento das mídias sociais deu voz à comunidade negra para denunciar tais atitudes. Essas tecnologias também servem para a comunidade lutar contra o preconceito e promover a sua identidade cultural e ancestral. As mídias sociais servem como uma preciosa ferramenta para promover a igualdade social. Contudo, algumas pessoas as utilizam também para disseminar preconceito com palavras ofensivas e brincadeiras de mau gosto. Discursos de ódio são encontrados diariamente por toda a internet, e esse tipo de violência, seja com a comunidade negra ou outra que foge aos padrões da sociedade, é também chamado de cyberbullying ou violência virtual. Podemos então perceber como o racismo pode atuar de diferentes maneiras, estigmatizando mais uma vez o povo negro.

Tudo o que foi apresentado até aqui nos leva a pensar em como o negro consegue viver em meio a tanto racismo, preconceito esse que não 
quer permitir sequer que o negro busque refúgio em religiões de matrizes africanas. O Brasil é um país cuja maior parte da população é cristã, em que muitos satanizam religiões como o candomblé e a umbanda, ambas de matrizes africanas, desrespeitando a diversidade cultural.

A exemplo do eurocentrismo, "Jesus Cristo" - a divindade sagrada das religiões cristãs - geralmente é descrito como alguém branco, loiro, com cabelos lisos e olhos azuis, porém essa descrição nada se parece com aquela elaborada pelos judeus que viviam à época de Cristo; o "embranquecimento" chegou aos céus. Esse "Jesus Cristo" idealizado, com características europeias, em nada representa diversas comunidades, não somente a negra. É triste pensar que o negro possa não se permitir a exercer a religião com a qual se identifique por medo do estigma que isso poderá acarretar.

Apesar de já estarmos em pleno século XXI, o racismo ainda não foi completamente vencido, mas isso não tem impedido que negros e brancos conscientes lutem pela igualdade e pelo progresso do nosso país. Enquanto esse progresso de pensamento da nossa sociedade não acontece, sua promessa permanece escrita em nossa bandeira. Lutamos hoje trazendo a reflexão desse assunto para que um dia este solo seja "uma mãe gentil" para todos os seus filhos, independentemente da cor que carregam em suas peles.

\section{O GESTOR E O COMBATE AO RACISMO NA ESCOLA}

Antes de iniciarmos uma reflexão sobre o papel do gestor no combate ao racismo na escola, é válido refletirmos primeiro sobre o papel da educação. Se procurarmos um conceito para educação, veremos uma infinidade de concepções; em linha geral, a educação é o processo de ensino-aprendizagem. Ela pode ocorrer em diferentes lugares de maneira intencional ou não, pois esse processo pode ser realizado a partir da observação do aprendiz (BRANDÃO, 2006). 
Porém, foi criado um ambiente específico para que o ensino-aprendizagem dos saberes sistematizados descobertos por nossa sociedade, nossa cultura e nossa história fossem repassados de geração a geração; esse ambiente recebeu o nome de escola. É nessa instituição onde ensinamos e aprendemos também valores e auxiliamos os nossos educandos a serem bons cidadãos e a praticarem a cidadania. Com eles, refletimos sobre distintos temas pertinentes em nossa sociedade, levando-os à construção dos conceitos de certo e errado, ensinando-os a pensarem primeiro no bem comum, para só então pensarem no bem individual. Sobre educação, Nascimento (2010, p. 5-6) enfatiza que:

Falar em educação é acreditar que o pleno desenvolvimento de uma criança só é efetivo quando ela passa por um processo de escolarização institucional. Isso não significa dizer que o sujeito só aprende na escola e que os outros ambientes sociais não sejam importantes, mas que para nossa sociedade a educação oferecida no espaço educativo é fundamental para o pleno desenvolvimento do indivíduo, principalmente nos anos iniciais de sua vida. Deste modo, a socialização recebida na infância é significativa para o desenvolvimento dos futuros cidadãos. [...] é possível compreender a educação como um exercício de construção de conhecimentos, formando cidadãos críticos com outra mentalidade, perante o sistema, sua organização e relações sociais estabelecidas entre os sujeitos sob uma visão de país globalizado e antiexclusivo.

Por essa razão, a escola é um espaço para novas ideias e reflexões e para a construção de valores; é local ideal para refletirmos sobre diversos saberes e descobertas das ciências. Com relação à escola, Rodrigues (2011, p. 11) diz que: "Se a exclusão escolar tem 'cor', é imprescindível compreendermos o papel de todos os atores escolares, [...] na implementação de programas e ações de promoção da igualdade racial". Dessa maneira, a questão do preconceito racial pode ser um tema a perpassar todas as aulas na instituição, por ter sido um erro cometido há muitos e muitos anos - mais especificamente de 1538 a 1888 (primeiro registro): a escravidão - e também por ainda permanecer em nossa 
sociedade brasileira, exigindo discussões e providências para que a garantia do direito de todos seja assegurada.

Não há nada que possamos fazer para apagar esse erro da nossa história, mas, ao falarmos sobre ele, discutirmos e refletirmos juntamente com as gerações futuras, impediremos que tal erro não seja mais cometido e, de maneira direta e indireta, combateremos um mal que infelizmente tornou-se atemporal: o racismo.

Tendo conhecimento da importância do ensino e reflexão atinente ao respeito ao negro, sua história, cultura e religião, sancionou-se em 2003, durante a vigência do mandato do então presidente Luiz Inácio Lula da Silva, a Lei 10.639, com o objetivo de tornar obrigatório o ensino sobre História e Cultura Afro-Brasileira nos estabelecimentos de Ensino Fundamental e Médio, oficiais e particulares. É uma missão da escola construir a igualdade social com seus alunos, para que o ensinamento rompa os muros da escola e vá além, permitindo que no futuro a nossa sociedade seja justa e sem qualquer preconceito racial. $O$ ensino à diversidade também é garantido pela Lei de Diretrizes e Bases da Educação Brasileira (LDB), Lei n 9.394, de 20 de dezembro de 1996:

Art. 26-A. Nos estabelecimentos de ensino fundamental e médio, oficiais e particulares, torna-se obrigatório o ensino sobre História e Cultura Afro-Brasileira. $\S 1^{\circ} \mathrm{O}$ conteúdo programático a que se refere o caput deste artigo incluirá o estudo da História da África e dos Africanos, a luta dos negros no Brasil, a cultura negra brasileira e o negro na formação da sociedade nacional, resgatando a contribuição do povo negro nas áreas social, econômica e política pertinentes à História do Brasil. § $2^{\circ}$ Os conteúdos referentes à História e Cultura Afro-Brasileira serão ministrados no âmbito de todo o currículo escolar, em especial nas áreas de Educação Artística e de Literatura e História Brasileiras.

A Lei $n^{\circ} 10.639 / 2003$ relembra que o calendário escolar incluiu o dia 20 de novembro como o "Dia Nacional da Consciência Negra". Infelizmente, se analisarmos o ensino da Educação Básica, incluindo os dias atuais, observaremos que os conteúdos referentes à História e Cultura Afro-Brasileira 
nos foram passados à luz da pedagogia tradicional, em que a História Africana foi marginalizada e excluída. Essa forma de concepção trouxe vários problemas, dentre eles o do racismo, acentuando a supremacia da cor branca como pertinente aos sujeitos heroicos, que mereciam ser contemplados como seres de cultura.

Além da LDB, as Diretrizes Curriculares Nacionais (DCNs) e os Parâmetros Curriculares Nacionais (PCNs), ambos da década de 1990, são documentos norteadores pedagógicos que ressaltam também a importância de se trabalhar os diversos tipos de manifestações sociais, sendo que essa temática recebeu destaque nesses parâmetros que trata sobre temas transversais.

Então, se sabemos da importância da educação e da escola no combate ao racismo, de tal forma que a lei ampara e torna obrigatório o estudo da História da África e da formação da população brasileira, recebendo o reforço na $\mathrm{LDB}$, DCNs e PCNs, como educadores temos o dever de trabalhar assuntos importantes como esse em sala de aula. Macedo $(2014$, p. 4) explica que:

\begin{abstract}
A necessidade de se debater e se trazer para a sala de aula a realidade vivenciada pela sociedade é inquestionável. É de suma importância que uma escola prime pelo cumprimento de diretrizes e parâmetros educacionais que busquem a equidade de direitos. Tais escolas precisam ser lideradas por gestoras(es) sensiveis e compromissadas(os) com a responsabilidade social e também legal, condizentes com os diversos documentos e convenções legais que se pautam nessa perspectiva.
\end{abstract}

A escola, desse modo, além do ato de educar, cumpre o papel de desconstruir e construir novos conceitos, mas, para que isso ocorra e para que a lei e os nossos norteadores sejam cumpridos, um personagem importante também deve cumprir o seu dever, o gestor escolar. Para que a sua importância fique clara, é válido refletirmos sobre o papel desse profissional em uma unidade escolar. 
O gestor escolar ocupa diferentes funções em uma escola, o seu papel é bem complexo, pois administra a parte financeira e pedagógica, lidando com pais, alunos, professores e funcionários. Ele possui múltiplas funções e por isso tem como apoio a equipe gestora, sendo o líder de tal equipe e também o exemplo. Nada acontece na escola sem a permissão da direção, por essa razão é que o diretor é tão importante no combate à discriminação racial dentro da escola. Deve partir dele o interesse de se fazer cumprir a lei. É papel desse profissional, junto com a comunidade escolar, incluir no Projeto PolíticoPedagógico (PPP) de sua escola o ensino da História Africana, a verdadeira história do nosso país e a importância dos afro-brasileiros, o respeito à cultura e à religião de matrizes africanas e o respeito aos afro-brasileiros.

Faz parte da função de ser gestor oferecer um ambiente agradável e propício ao ensino-aprendizagem, por isso qualquer tipo de preconceito deve ser combatido e erradicado dentro da escola, e a forma mais eficaz de se combater a ignorância é trazendo o conhecimento para a roda de conversa. Apoiar o estudo de temas como o racismo vai muito além do que cumprir uma lei, traz benefícios visíveis e incontestáveis para a escola. Segundo Pimentel, Silva e Santos $(2015$, p. 15):

\begin{abstract}
A escola é um ambiente privilegiado para se iniciar o processo de conhecimento da diversidade cultural brasileira e promoção de respeito a todas as diferenças decorrentes desta pluralidade, uma vez que é um espaço onde convivem crianças de várias etnias, classes sociais, crenças e culturas distintas; podendo direcionar o aprendizado ao respeito mútuo e o convívio democrático com a diferença.
\end{abstract}

Omitir-se antes os preconceitos raciais que ocorrem dentro da escola é como ratificá-los, sendo papel não só do gestor como também de todos que trabalham em uma instituição de ensino combater qualquer atitude errônea realizada por parte dos educandos. O número de evasão dentro das escolas é alarmante, principalmente o da criança negra. "Por meio de vários dados estatísticos, verifica-se que há uma grande evasão escolar de crianças e jovens negras(os), assim como de desigualdades no rendimento educacional em comparação às crianças brancas" (MACEDO, 2014, p. 5). 
Não é coincidência que o número de crianças negras a se evadirem da escola é maior do que o número de crianças brancas. Nós permanecemos em um ambiente quando este está sendo acolhedor, quando as pessoas ao nosso redor nos respeitam. É válido lembrar que a escola é composta por membros da sociedade; se a nossa sociedade é racista e se sabemos que as crianças tendem a imitar os adultos, há grandes chances de o racismo também estar presente no ambiente escolar, partindo, às vezes, não só por parte do alunado. É mais uma vez tarefa do gestor estar atento a qualquer situação atípica.

Sabemos que estar à frente de uma escola não é uma tarefa fácil, são diversas funções e problemas a serem resolvidos. Porém, em primeiro lugar, deve estar o bem-estar, o ensino-aprendizagem do educando e a sua formação cidadã, por isso é imprescindível não permitir que o bulliyng aconteça ou continue acontecendo, seja qual for o motivo que o faça ocorrer. Assuntos importantes também devem ser discutidos, afinal não é só de "matérias curriculares" que se vive uma escola. As leis, como a $\mathrm{n}^{\circ}$ 9.394/1996 e a $n^{\circ} 10.639 / 2003$, devem ser seguidas. No tocante à discussão do papel do gestor à frente da escola no combate ao racismo, Rodrigues $(2011$, p. 6) assevera que:

O objetivo desse debate não é culpar o/a gestor/a pela existência e perpetuação do racismo educacional, mas evidenciar a importância do seu papel e especialmente de sua formação, tendo em vista que o desconhecimento pode definir o retrocesso das políticas públicas de promoção da igualdade racial. Os/as gestores/as educacionais assumem papel de liderança e função de chefes imediatos/as dos/as profissionais da educação que atuam na escola, o que permite significativa possibilidade de influenciar o perfil das relações raciais no ambiente escolar por meio da construção coletiva dos mecanismos de superação pautados nos pressupostos de uma educação antirracista, uma vez que desempenham funções administrativas e pedagógicas que atingem toda a comunidade escolar.

Em suma, o principal papel do gestor é fazer a diferença no ambiente que trabalha e para quem ele trabalha, por isso é papel dele combater 
qualquer tipo de intolerância na escola que está sob seus cuidados, inclusive o racismo.

\section{METODOLOGIA}

Utilizamos a pesquisa qualitativa (KAUARK; MANHÃES; MEDEIROS, 2010) e o estudo de caso (PRODANOV; FREITAS, 2013). Realizamos a pesquisa de campo em duas escolas do bairro Curió, município de Fortaleza-CE4 ${ }^{4}$ Tivemos a intenção de abordar duas realidades bem distintas de uma mesma localidade para observarmos se há racismo em ambas e como ele é combatido pelos gestores dessas instituições.

A primeira escola visitada faz parte da rede pública de ensino e atende a crianças da Educação Infantil e dos anos iniciais do Ensino Fundamental. Está localizada no Conjunto Sítio Curió. No seu entorno, há residências, muitas árvores, campos de futebol, quadras de futsal e uma igreja católica. À primeira vista, percebemos que a escola é bastante ampla; o nome da instituição está exposto na entrada e também no muro, com letras maiores. Se não houvesse tantas pichações à frente da unidade escolar, seria belíssima e harmonizaria com as árvores à sua volta.

A entrada à instituição se dá por um portão estreito que nos leva ao pátio da escola, onde ficam as mesas em que as crianças lancham. Por ser um ponto central, do pátio temos a visão das salas, da secretaria, da diretoria, da cantina, da biblioteca, dos banheiros, etc. Apesar de ter uma estrutura antiga, com a necessidade de realização de alguns reparos, percebemos o zelo dos profissionais que lá trabalham em cuidar e manter os espaços limpos. É uma escola bastante arejada e privilegiada pela natureza, por ter árvores e flores dentro do prédio.

\footnotetext{
${ }^{4}$ Inicialmente tínhamos o objetivo de realizar esta pesquisa em escolas da Messejana, no entanto tanto as escolas públicas como as privadas se opuseram à realização da pesquisa, demonstrando certa desconfiança em relação à entrevista. Apresentamos os documentos e as perguntas que seriam feitas, nem assim recebemos um retorno positivo. Diante disso, optamos por realizar a pesquisa em um bairro vizinho, o Curió.
} 
A segunda escola visitada faz parte da rede privada de ensino. Ela é considerada pelos moradores da região a maior do bairro Curió, contando com alunos dos bairros vizinhos e até maiores que o Curió, como é o caso do bairro Messejana. O seu alunado é composto de crianças de classe média, diferentemente do alunado da escola visitada anteriormente. A escola atende a crianças da Educação Infantil ao Ensino Fundamental, tendo inclusive semi-internato e preparatório para o Instituto Federal de Educação, Ciência e Tecnologia do Ceará (IFCE).

A unidade escolar situa-se dentro de um grande sítio, tornando o ambiente agradável à primeira vista. Próximo à institiução, há diversas residências, um supermercado, uma quadra de esportes, igrejas, padaria, pontos de ônibus, pizzaria e lojas. As ruas, em sua maioria, são asfaltadas, havendo em todas a presença de árvores e outras plantas. Como a maior parte dos prédios são residenciais, é comum encontrarmos crianças brincando ou idosos nas calçadas em qualquer horário do dia, dessa forma é possível afirmar que o entorno é tranquilo, bastante familiar e aconchegante.

A fachada é coberta por azulejos que revelam as cores oficiais da escola, branco e o verde-escuro. Na entrada, não há rampas, mas o batente (que separa a escola da rua) é baixo e o portão da entrada é bastante largo, assim como as portas dos banheiros. A escola é bem ampla, tem dois andares, apresentando como atrativos para as crianças: biblioteca, sala de informática, sala de dança, sala de karatê, sala de vídeo, brinquedoteca, duas piscinas, quadra poliesportiva, salão de jogos, pátio, playground, parquinho, fazendinha (local em que ficam os animais) e todo o espaço do sítio. Todos esses ambientes nos foram apresentados pela supervisora da instituição enquanto esperávamos para falar com a diretora.

Encontramos algumas dificuldades para a realização da pesquisa: a recusa das escolas de nos receberem; a mudança no campo de pesquisa; e principalmente o mês em que foi realizada. No mês de setembro, no dia 7 é comemorado o Dia da Independência do Brasil, porém, por ser feriado 
nacional, nem todas as escolas comemoram nesse dia. Dentre as atividades programadas, destacamos o ato de marchar, o hasteamento da bandeira e o canto do Hino Nacional, além da prática de pedagogia de projetos com temáticas voltadas para essa data comemorativa tão importante para a sociedade brasileira. Acreditamos que essas comemorações nos trouxeram dois problemas: a dificuldade de nos receberem nas escolas e a alegação de falta de tempo para participarem da pesquisa.

Para esta pesquisa, escolhemos dois sujeitos que fazem parte da gestão escolar e que atuam de maneiras diferentes nas escolas em que trabalham. O primeiro sujeito entrevistado foi uma coordenadora da escola pública, a qual denominamos de CEPU para mantermos a sua identidade em sigilo. Ela atua como coordenadora pedagógica nos turnos da manhã e da tarde, para isso possui graduação em Pedagogia, com especialização em Gestão Escolar e Psicopedagogia Institucional. Tem 49 anos de idade e trabalha há 19 anos na educação, estando há quatro anos nessa instituição.

O outro sujeito exerce o duplo papel de diretora e coordenadora na escola privada campo desta pesquisa, sendo denominada de DEPr. Ela, com 37 anos, fundadora da referida escola, trabalha nos turnos da manhã e da tarde há nove anos. Possui graduação em Pedagogia, com especialização em Psicopedagogia, tendo 18 anos de experiência na área da educação.

Utilizamos a entrevista semiestruturada como instrumental (POLAK; SANTANA; ARAÚJO, 2014; PRODANOV; FREITAS, 2013). As entrevistas aconteceram nas próprias instituições de ensino nos dias 12 e 13 de setembro de 2017, sendo registradas a lápis em um diário de campo. O uso de celular ou de registros fotográficos foram negados pelas entrevistadas. $O$ emprego de filmadora sequer foi levado em consideração por nós, pesquisadores, por receio da desistência das entrevistadas em participarem da pesquisa. Quanto aos documentos escolares, como o PPP, não tivemos acesso a eles em nenhuma das instituições de ensino em que a pesquisa aconteceu. 


\section{ANÁLISE DOS DADOS}

Sobre a escola pública, no dia da entrevista, o porteiro nos recebeu com muita gentileza e nos apresentou à coordenadora, que também nos recebeu muito bem, pedindo apenas que esperássemos um pouco até que nos atendesse. Após uns dez minutos, ela nos atendeu no pátio da escola, onde sentamos nas mesinhas, circunstância em que ela nos pediu desculpas pela demora e justificou-se dizendo que aquele dia estava um pouco atípico.

Em seguida, apresentamo-nos à coordenadora e explicamos os motivos que haviam nos levado à escola naquela tarde de setembro. Ela aceitou realizar a entrevista, mas nos informou que a diretora estaria ocupada naquele dia e nos próximos também; não cometemos a indiscrição de perguntar o motivo de a diretora não poder nos receber, até porque sabemos das inúmeras tarefas exercidas por ela, principalmente quando a escola é pública. Decidimos então realizar a entrevista com a coordenadora, que nos recebeu tão gentilmente.

Perguntamos-lhe se havia problemas na gravação da entrevista com celular; ela disse que preferia que as respostas fossem escritas com papel e caneta; revelou também que preferia que não houvesse qualquer registro fotográfico, pois a diretora da escola poderia não gostar. Ela perguntou quanto ao sigilo da pesquisa, ocasião em que the informamos que seria respeitado em todas as etapas, por essa razão o nome da escola e da própria coordenadora foram preservados. Apresentamos-lhe os documentos que levamos, a saber: a declaração da universidade e o Termo de Consentimento Livre e Esclarecido (TCLE).

No tocante à instituição particular, conhecemos a diretora, que também é a coordenadora pedagógica e a dona da escola. Relembramos que havíamos ligado no dia anterior ao da entrevista para the apresentar a declaração que nos foi dada pela Universidade Estadual do Ceará (UECE) a fim de que pudéssemos visitar as escolas. Ela leu e nos pediu para ver previamente quais seriam as perguntas realizadas durante a entrevista. Após ler as perguntas, ela concordou em nos conceder a entrevista. Assim como a 
gestora da primeira escola, ela preferiu que a entrevista fosse registrada a lápis e papel.

Em relação às questões do roteiro de entrevista, a primeira pergunta era se havia algum projeto na escola que abordasse sobre o tema racismo. Elas responderam:

CEPU - Já trabalhamos de acordo com a lei, mas nada muito específico. Foi trabalhado em sala de aula, de acordo com a série, como conteúdo abordado em sala. Nunca houve uma situação gritante. Os pequenos casos que apareceram foram alguns apelidos, e os mesmos foram resolvidos com naturalidade pelos professores e pela gestão.

DEPr - No momento, não, mas já foi realizado um projeto racial nos anos iniciais do Ensino Fundamental; [quanto às situações-problema]: sim, já houve, mas foram poucos casos, e estes logo foram resolvidos de maneira sábia pelas professoras. As mesmas com os alunos trabalharam obras literárias sobre o tema, como o livro Menina bonita do laço de fita, E pele tem cor, entre outros.

Houve uma identificação do problema nas duas escolas e providências foram tomadas. No entanto, não havia até então nenhum projeto em vigor nas duas instituições para o combate ao racismo e/ou um projeto de cultura africana ou valorização da raça negra. A CEPu afirmou que já havia trabalhado dentro da lei, já a DEPr não a citou em momento nenhum. Gonçalves (2009, p. 7) explica que:

Sabemos que muitos professores não têm a oportunidade de fazer um curso de qualificação voltado para a relação étnico-racial, por esse motivo os mesmos deixam a desejar quando se trata da temática em questão, e muitas vezes, por falta de preparo ou por preconceitos introjetados, alguns professores não sabem se aproveitar das situações flagrantes de discriminação racial na escola. Há momentos pedagógicos privilegiados para discutir a diversidade e conscientizar alunos sobre sua importância e riqueza, onde o objetivo de todos é dar sua contribuição e ajudar nesse processo transformador tão necessário e urgente.

Outra informação que nos chamou a atenção foi quando a CEPu explicou que o racismo em sua escola havia sido combatido pelos 
professores e pela gestão. Já a DEPr citou apenas a ação das professoras, o que nos leva à indagação sobre o apoio da DEPr naquele momento. Pudemos observar também o fato de serem duas instituições de realidades distintas, mas isso não impediu que situações racistas ocorressem nas duas unidades. Consoante Rodrigues (2011, p. 4):

A escola reproduz um modelo de sociedade, naturaliza o racismo e cria um padrão único de beleza, cultura, linguagem, aos quais todos/as devem seguir. O discurso presente na escola - nas falas, comportamentos, livros didáticos, festividades, etc. -, além da imposição de valores, contribui significativamente para a manutenção da discriminação racial por meio da negação de nossas origens e reprodução diária de um modelo discriminatório de sociedade.

Na pergunta seguinte, expusemos uma situação hipotética em que uma criança do $2^{\circ}$ ano do Ensino Fundamental praticava racismo contra outra criança em sala de aula. Questionamos então qual seria a alternativa mais acertada por parte da gestão diante dessa situação. Elas nos responderam:

CEPu - Deveria haver (ter) um diálogo com as duas crianças envolvidas. Estendendo depois para a sala de aula, aproveitando o acontecimento para ressaltar a importância de cada um para nós, para a família e para a sociedade, independentemente de qual seja a cor que ela tenha.

DEPr - A primeira ação por parte do gestor seria conversar com o aluno que está agindo com preconceito, tentando primeiramente descobrir o que o levou a agir de forma preconceituosa, mostrando que essa sua atitude é bastante incorreta e que eu não aceito esse tipo de 'brincadeira' na minha escola. Em seguida, falaria com a criança que foi vítima do preconceito e diria o quanto ela é importante, o quanto todas as pessoas são únicas e, por isso, especiais. Explicaria que a cor da pele é apenas uma característica entre muitas outras que ela tem, que todos temos características e são elas que nos tornam diferentes e, portanto, especiais e únicas. Diria que a cor da pele dela é tão linda quanto a de qualquer outra pessoa na escola. Depois conversaria com a professora deles e pediria para que não deixasse esse acontecimento 'passar batido', pediria para ela trabalhar sobre racismo em sua próxima aula de ética. Temos muito material disponível para combater qualquer tipo de bullying e também o racismo. Se eu percebesse que o caso

Revista Exitus, Santarém/PA, Vol. 9, N² 2, p. 263 - 291, ABR/JUN 2019. 
estava mais sério e fosse rotineiro ou que estivesse acontecendo em outras salas de aula, eu faria uma reunião com os professores e criaríamos um projeto para combater de forma mais enfática o racismo. Em casos mais severos, conversaria também com os pais da criança agressora.

Nessa questão, podemos ver uma resposta complementando a outra. No entanto, a criação de um projeto antirracista não foi pensada pela CEPu. Foi citado pela DEPr como uma última alternativa, quando o problema já tivesse uma proporção maior. Todas essas situações poderiam ser minimizadas ou extintas se já existisse um projeto vigente. Não obstante, percebemos pelas duas falas que o racismo é visto como um problema pequeno, que não exige tanta preocupação ou esforço por parte da gestão escolar, e essa é uma forma equivocada de avaliar o racismo. Sabemos que o diálogo é sempre indispensável, mas a prática contra o racismo também o é, sobretudo partindo de integrantes da escola ou do diretor.

Por essa razão, sentimos falta da abordagem das leis que embasam a luta contra o racismo e da valorização cultural histórica e ancestral africana nessas escolas como assuntos constantes a serem trabalhados nas aulas como temas essenciais que perpassam o processo de ensino-aprendizagem dos conteúdos. Sobre o assunto, enfatiza Pinho (2014, p. 77):

\begin{abstract}
Assim, a questão da discriminação racial aos negros ou aos descendentes africanos não é tratada de modo reflexivo, levando em conta a realidade em sala de aula. A escola e os professores precisam rever valores e princípios arraigados a concepções do mundo e das pessoas que justificam práticas e sentimentos racistas.
\end{abstract}

No quarto questionamento, indagamos se havia empecilhos que pudessem dificultar o trabalho do núcleo gestor no combate ao racismo:

CEPu - Atualmente não vejo empecilhos, pois há muitos recursos para serem utilizados. A internet nos abriu um leque de ferramentas a que podemos ter acesso a qualquer hora, em qualquer lugar e para todas as faixas etárias. Antigamente, sim, pois não havia tantas possibilidades como temos hoje. 
DEPr - Aqui na escola não há nada que dificulte tanto o trabalho do núcleo gestor quanto o trabalho da gestão. O que pode ocorrer em outras escolas é a falta de sensibilidade dos gestores em combater o racismo. É não saber se colocar no lugar do outro. E pode também haver uma falta de recursos para isso, mas esse caso acho pouco provável, por conta da internet.

Essas duas respostas foram muito semelhantes. Realmente temos inúmeras ferramentas atualmente para utilizarmos em projetos ou aulas que abordem essa temática. Entretanto, durante as entrevistas, percebemos que a superficialidade das respostas podem deixar margem para pensarmos que algumas questões possam se tornar empecilho, a exemplo da inclusão deste tema - racismo - e de outros como pertencentes ao currículo de forma mais concisa e também o fato de não se ter menções às leis de forma mais enfática. Quanto à legislação brasileira, Macedo (2017, p. 393) acentua que:

A Lei de Diretrizes e Bases da Educação (LDB 9.394/1996) reforça a necessidade de institucionalização da Educação das Relações Étnico-Raciais e da História e Cultura Afro-Brasileira e Africana. Vislumbrando a necessidade de mudanças substantivas na política de formação inicial e continuada para professoras/es e gestoras/es, essa formação deverá, portanto, de acordo com as prescrições e orientações normativas, contemplar o estudo da diversidade étnico-racial.

Na quinta questão, solicitamos a opinião sobre qual seria o papel da gestão no combate ao racismo. Assim nos responderam as gestoras:

CEPu - É educativo, trazendo sempre informação para os nossos educandos, ensinando valores como: o respeito, a compaixão, como tratar o outro, como agir em sociedade no modo geral ou com o próximo.

DEPr - A gestão exerce um papel primordial no combate a qualquer tipo de preconceito, é nosso dever nos impor a qualquer tipo de bullying, expondo aos nossos educandos o quanto isso é errado, e não é só dizendo 'isso não pode'. Devemos ensiná-los que é errado e por que é errado. É dando suporte aos professores para abordarem esse tema em sala de aula. É pensar junto com eles qual a melhor maneira de dissipar esse mal (o preconceito) da nossa escola, oferecendo total apoio para as vítimas e muita informação para quem age de forma racista, trabalhando valores com eles, principalmente o respeito ao próximo.

Revista Exitus, Santarém/PA, Vol. 9, N² 2, p. 263 - 291, ABR/JUN 2019. 
Mais uma vez, podemos observar a semelhança entre as respostas. Tudo que foi descrito pelas entrevistadas faz parte do "ser gestor". A respeito do assunto, Castro, Almeida e Freitas $(2014$, p. 6) destacam algumas possibilidades que podem contribuir para a discussão sobre o racismo na escola e/ou em sala de aula:

[...] realizar atividades, projetos, palestras que deem abertura a essa discussão para que não só o aluno, mas toda a equipe escolar perceba que é fundamental realizar essa inclusão para se viver com respeito e ética as relações sociais. Assim, a visão dessa representação pode desenvolver também nos alunos não negros preconceitos quanto à capacidade intelectual da população negra e, nas crianças negras, um sentimento de incapacidade que pode conduzi-las ao desinteresse, à repetência e à evasão escolar.

Após as entrevistas, percebemos como os gestores podem influenciar positiva ou negativamente no bem-estar e na permanência do aluno negro na escola. Com o seu exemplo e atitude, podem transformar a própria prática docente dos professores de sua instituição. O primeiro e mais difícil empecilho é vencer o preconceito que nos foi enraizado desde a nossa mais tenra idade. Vale ressaltar a falta também de uma qualificação (formação continuada) para gestores e professores trabalharem temáticas como a valorização étnico-racial. No tocante à disponibilidade de recursos, temos ao nosso alcance números expressivos, mas que de nada valerão se não soubermos ou não quisermos utilizá-los.

A escola é apenas uma pequena parcela da nossa sociedade, por isso o racismo está presente em todas as instituições de ensino, sejam públicas ou particulares. E o combate ao racismo não se esgota com uma aula ou um desenho para colorir no Dia Nacional da Consciência Negra, é um trabalho árduo e diário que jamais deve ser banalizado ou visto como algo "natural", porque não é natural uma criança agir com preconceito, seja ele qual for. E se elas se espelham em adultos para agir com tamanho desdém aos sentimentos do próximo, que não sejamos os adultos a dar esse 
exemplo. Façamos a nossa parte; se já atuamos como professores ou gestores, façamos a diferença na educação e vida dos nossos educandos.

\section{CONCLUSÃO}

Com base nas fontes que apresentamos no decorrer deste artigo, observamos que o racismo é um mal que está instalado no seio da sociedade desde a época do Período Colonial e já deveria ter sido extirpado. Mas, por estar entre nós, envenenando pessoas e maltratando outras há tanto tempo, é difícil realmente acabá-lo de uma hora para a outra. Aos poucos, ele vem perdendo o seu espaço para o conhecimento e para o respeito, graças à luta diária de pessoas que se orgulham de ter em sua origem uma raiz africana. As leis e a escola como instituição social têm auxiliado nessa luta pelo direito de ser como é, de não ter vergonha da sua história e de ser respeitado por isso.

Racismo é crime, é injustificável, é algo que devemos dissipar de nossas escolas, pois as nossas crianças, que são o futuro do nosso país, precisam aprender a respeitar o próximo. Esse combate que nasce em salas de aula deve ser levado para além dos muros da escola. Pensando assim, podemos perceber que as mudanças (por respeito) que tanto buscamos podem começar através de uma decisão nossa: agir e não se omitir.

Respondendo à pergunta "Qual o papel do gestor no combate ao racismo nas séries iniciais do Ensino Fundamental?", podemos indicar que a resposta é principalmente o de educar; é o de ensinar a criança a tratar os outros com respeito; é o de, quando ela fizer algo errado, mostrar-Ihe que está errando; é o de ajudá-la a fazer o certo novamente. É papel do gestor dialogar com a criança, com a sua professora e também com os seus pais, tendo o intuito de compreender o que está se passando com aquela criança para ela estar agindo daquela forma. É função do gestor como líder incentivar os docentes a combaterem qualquer situação de preconceito e/ou de bullying, fornecendo recursos para isso. É não permitir que tais situações de racismo ocorram em sua escola. É função do gestor ser 
exemplo, sendo o primeiro a fazer algo para combater o racismo sempre que ele surgir.

Consideramos relevante a troca de conhecimentos com duas profissionais com tempo na educação e na função de gestoras. Além disso, pudemos trazer duas realidades de um mesmo bairro, com características distintas sobre a abordagem do racismo. Ambas entrevistadas revelaram que o tema é tratado com diálogo, que há a participação da gestão para a resolução de problemas, que se tem ciência dos recursos disponíveis para trabalhar o tema; de outro ângulo, mostraram pouca desenvoltura no tocante a leis e a trabalhos com projetos nas escolas que abordem 0 racismo de forma mais constante como parte do currículo escolar.

Defendemos a ideia de que mudanças de pensamentos se iniciam primeiro no ambiente acadêmico, influenciando futuros profissionais, e de que serão estes que irão propagar esse novo jeito de pensar, o que se refletirá também nas práticas tanto dos profissionais como daqueles que irão tê-los como exemplos. Por essa razão, fazemos apologia veementemente à importância de mais uma vez discutirmos esse assunto e refletirmos sobre nossas práticas como futuros gestores, professores, profissionais da educação, líderes de uma comunidade escolar. Somos nós primeiramente que devemos nos apropriar de discursos contra qualquer tipo de preconceito, pois trazem danos e interferem nos direitos humanos, devendo, portanto, ser extirpados do nosso meio.

A mudança que tanto buscamos e queremos nasce nas escolas, faculdades e universidades e anda junto com uma educação de qualidade, sob a supervisão de gestores sensiveis aos problemas que afligem a sociedade e de educadores reflexivos, inspiradores e transformadores.

\section{REFERÊNCIAS}

BRANDÃO, C. O que é educação. São Paulo: Brasiliense, 2006. 
BRASIL. Lei $n^{\circ} 7.716$, de 5 de janeiro de 1989. Define os crimes resultantes de preconceito de raça ou de cor. Diário Oficial [da] República Federativa do Brasil, Poder Executivo, Brasília, DF, 6 jan. 1989.

BRASIL. Lei n 9.394, de 20 de dezembro de 1996. Estabelece as Diretrizes e Bases da Educação Nacional. Diário Oficial [da] República Federativa do Brasil, Poder Executivo, Brasília, DF, 21 dez. 1996.

BRASIL. Lei no 10.639, de 9 de janeiro de 2003. Altera a Lei no 9.394, de 20 de dezembro de 1996, que estabelece as Diretrizes e Bases da Educação Nacional, para incluir no currículo oficial da rede de ensino a obrigatoriedade da temática "História e Cultura Afro-Brasileira", e dá outras providências. Diário Oficial [da] República Federativa do Brasil, Poder Executivo, Brasília, DF, 10 jan. 2003.

BRASIL. Lei $n^{\circ} 12.711$, de 29 de agosto de 2012. Dispõe sobre o ingresso nas universidades federais e nas instituições federais de ensino técnico de nível médio e dá outras providências. Diário Oficial [da] República Federativa do Brasil, Poder Executivo, Brasília, DF, 30 ago. 2012.

BRASIL. Parecer CNE/CP n 3, de 10 de março de 2004. Diretrizes Curriculares Nacionais para a Educação das Relações Étnico-Raciais e para o Ensino de História e Cultura Afro-Brasileira e Africana. Diário Oficial [da] República Federativa do Brasil, Poder Executivo, Braślia, DF, 19 maio 2004.

BRASIL. Secretaria de Educação Fundamental. Parâmetros Curriculares Nacionais: História, Geografia. Secretaria de Educação Fundamental. Brasília, DF: MEC/SEF, 1997.

CASTRO, A. R. F.; ALMEIDA, J. R. P.; FREITAS, S. F. Racismo na escola: o livro didático em discussão. Campina Grande: Realize, 2014.

GONÇALVES, F. L. C. O papel da escola na desconstrução do racismo, preconceito e discriminação: a fomentação profissional dos educadores da Escola Estadual de Ensino Fundamental Presidente Castelo Branco. 2009. Trabalho de Conclusão de Curso (Especialização em Educação para Relações Étnico-Raciais) - Programa de Pós-Graduação em Educação para Relações Étnico-Raciais, Instituto Federal de Educação, Ciência e Tecnologia do Pará, Belém, 2009.

KAUARK, F.; MANHÃES, F. C.; MEDEIROS, C. H. Metodologia da pesquisa: guia prático. Itabuna: Via Litterarum, 2010.

MACEDO, A. Gestão escolar e educação antirracista: a implementação da Lei 10.639/2003 na perspectiva da educação como direito. Brasília, DF: UnB, 2014. 
MACEDO, A. Negar, silenciar, apagar: a gestão escolar frente à educação antirracista. Revista da ABPN, Goiânia, v. 9, n. 22, p. 385-408, 2017.

NASCIMENTO, A. E. J. Educação e preconceito racial no Brasil: discriminação no ambiente escolar. In: PESQUISA EM EDUCAÇÃO, DESENVOLVIMENTO, ÉTICA E RESPONSABILIDADE SOCIAL, 5., 2010, Maceió. Anais... Maceió, 2010.

PEREIRA, O. M. L. A dor na cor: reflexões sobre o papel do negro no Brasil. Cadernos Imbondeiro, João Pessoa, v. 2, n. 1, p. 1-10, 2012.

PIMENTEL, J. J. C.; SILVA, J. L.; SANTOS, N. A. M. Racismo na escola: um desafio a ser superado. Espírito Santo, 2015.

PINHO, J. S. Gestão e preconceito racial. Regae: Revista de Gestão e Avaliação Educacional, Santa Maria, v. 3, n. 5, p. 75-83, 2014.

POLAK, Y. N. S.; SANTANA, J. R.; ARAÚJO, H. L. M. R. Dialogando sobre metodologia científica. Fortaleza: UFC, 2014.

PRODANOV, C. C.; FREITAS, E. C. Metodologia do trabalho científico: métodos e técnicas da pesquisa e do trabalho acadêmico. Novo Hamburgo: Feevale, 2013.

RODRIGUES, R. M. M. Educação das relações étnicos-raciais e gestão escolar. Cadernos ANPAE, Goiânia, v. 1, p. 1-13, 2011.

SCHUCMAN, L. V. Racismo e antirracismo: a categoria raça em questão.

Revista Psicologia Política, São Paulo, v. 10, n. 19, p. 41-55, 2010.

SIQUEIRA, T. M. L. O trabalho escravo perdura no Brasil do século XXI. Revista do Tribunal Regional do Trabalho da $3^{a}$ Região, Belo Horizonte, v. 52, n. 82 , p. 127-147, 2010. 